\title{
Article \\ The Annealing Effect at Different Temperatures for Organic-Inorganic Perovskite Quantum Dots
}

\author{
Shui-Yang Lien ${ }^{1,2,3}$, Pin-Jia Lai ${ }^{4}{ }^{D}$, Wen-Ray Chen ${ }^{5}$, Chuan-Hsi Liu ${ }^{6}$, Po-Wen Sze ${ }^{7}$ and Chien-Jung Huang ${ }^{4, *}$ \\ 1 School of Opto-Electronic and Communication Engineering, Xiamen University of Technology, \\ Xiamen 361024, China; sylien@xmut.edu.cn \\ 2 Department of Materials Science and Engineering, Da-Yeh University, Dacun, Changhua 51591, Taiwan \\ 3 Fujian Key Laboratory of Optoelectronic Technology and Devices, Xiamen University of Technology, \\ Xiamen 361024, China \\ 4 Department of Applied Physics, National University of Kaohsiung, Kaohsiung University Rd., \\ Kaohsiung 81148, Taiwan; m1094302@mail.nuk.edu.tw \\ 5 Department of Electronic Engineering, National Formosa University, Wenhua Rd., Yunlin 632301, Taiwan; \\ chenwr@nfu.edu.tw \\ 6 Department of Mechatronic Engineering, National Taiwan Normal University, Heping East Rd., \\ Taipei 10610, Taiwan; liuch@ntnu.edu.tw \\ 7 Department of Electrical Engineering, Kao Yuan University, Zhongshan Rd., Kaohsiung 82151, Taiwan; \\ t20029@cc.kyu.edu.tw \\ * Correspondence: chien@nuk.edu.tw; Tel.: +886-7-5919475; Fax: +886-7-5919357
}

check for updates

Citation: Lien, S.-Y.; Lai, P.-J.; Chen, W.-R.; Liu, C.-H.; Sze, P.-W.; Huang,

C.-J. The Annealing Effect at Different Temperatures for

Organic-Inorganic Perovskite

Quantum Dots. Crystals 2022, 12, 204

https://doi.org/10.3390/

cryst12020204

Academic Editor: Shujun Zhang

Received: 20 December 2021

Accepted: 26 January 2022

Published: 29 January 2022

Publisher's Note: MDPI stays neutral with regard to jurisdictional claims in published maps and institutional affiliations.

Copyright: (C) 2022 by the authors. Licensee MDPI, Basel, Switzerland. This article is an open access article distributed under the terms and conditions of the Creative Commons Attribution (CC BY) license (https:// creativecommons.org/licenses/by/ $4.0 /)$
Abstract: After the preparation of inorganic perovskite cesium lead iodide quantum dots $\left(\mathrm{CsPbI}_{3}\right.$ $\mathrm{QD})$ by ligand-assisted reprecipitation ( $\mathrm{LARP}), \mathrm{CsPbI}_{3} \mathrm{QD}$ was added to the organic perovskite methylamine lead triiodide $\left(\mathrm{CH}_{3} \mathrm{NH}_{3} \mathrm{PbI}_{3} ; \mathrm{MAPbI}_{3}\right)$ to successfully form composite perovskite film. To obtain better perovskite quantum dot (PQD) crystal characteristics, this research used different annealing temperatures to discuss the crystallinity changes of perovskite quantum dots (PQD). Through X-ray diffraction (XRD) analysis, it was found that the preferred peak (110) of $\mathrm{MAPbI}_{3}$ had maximum peak intensity when the annealing temperature increased to $120^{\circ} \mathrm{C}$. Based on the measurement results of PQD's Ultraviolet-Visible spectrum, it was shown that the maximum absorption area was obtained at the wavelength of $350 \mathrm{~nm} 750 \mathrm{~nm}$ at the annealing temperature $120{ }^{\circ} \mathrm{C}$. From the scanning electron microscope (SEM) measurement, it was found that the grain size was the largest at the annealing temperature $120^{\circ} \mathrm{C}$, and the grain size was $60.2 \mathrm{~nm}$. The best crystallization characteristics of PQD were obtained at the annealing temperature $120^{\circ} \mathrm{C}$.

Keywords: perovskite; annealing; quantum dots; ligand-assisted reprecipitation; thermal stability

\section{Introduction}

Lead halide perovskite materials have attracted much attention in the past few years [1-3] because of their unique properties, such as low cost, the application of luminescent materials and their application in the field of optoelectronics [3,4]. Among the perovskite materials, methylamine lead triiodide $\left(\mathrm{CH}_{3} \mathrm{NH}_{3} \mathrm{PbI}_{3} ; \mathrm{MAPbI}_{3}\right)$ is suitable for solar cell absorber layers due to its wider excitation spectrum, better absorption capacity and higher carrier mobility [5-7]. However, there are also some shortages for $\mathrm{MAPbI}_{3}$. For example, $\mathrm{MAPbI}_{3}$ cannot be stored in the air for a long time because of its hygroscopicity of methylammonium (MA) cations and poor thermal stability [8]. This result will affect the efficiency of organic perovskite solar cells. Because of the above deficiencies, some literature has reported that the moisture/thermal stability and the optical properties of perovskite $\mathrm{MAPbI}_{3}$ films would be greatly improved by doping inorganic quantum dots [9-11]. For example, J.H Han et al. doped plumbous sulfide (PbS) quantum dots (QDs) into $\mathrm{MAPbI}_{3}$ film to enhance the photoelectric conversion efficiency of perovskite solar cell [12]. The treatment of thermal annealing is often used to remove the residual precursor solvent [13]. Besides, A. Natik 
et al. found that the grain size and energy band gap change with the annealing time [14]. At present, the synthesis of QDs is based on various methods, including hot injection, ligand-assisted reprecipitation (LARP), ultrasonication and solvothermal synthesis. In our work, $\mathrm{CsPbI}_{3}$, the inorganic perovskite quantum dot (PQD), was prepared by the LARP because its reaction product is a colloidal dispersion which is easy to expand by spin coating. Besides, the method is simple, with high processing rate and low temperature, so it is widely used for preparing quantum dots [15]. However, the annealing temperature and time are the key factors affecting the crystallization, performance and morphology of the PQD film [16]. By adding $\mathrm{CsPbI}_{3}$ PQD into the $\mathrm{MAPbI}_{3}$ solution and controlling the annealing temperature, it can enhance the stability of the perovskite structure. In this article, a detailed study for the formation ratio of organic-inorganic perovskites at the optimal temperature is also presented.

\section{Materials and Methods}

\subsection{Materials}

All materials contain lead (II) iodide (ACROS organic, $\mathrm{PbI}_{2}, 99.9985 \%$ ), cesium iodide (Alfa Aesar, Lancashire, UK, CsI, 99.9\%), oleyl amine (ACROS organic, Geel, Belgium, $\mathrm{C}_{18} \mathrm{H}_{35} \mathrm{NH}_{2}, 90 \%$ ), toluene ((J.T. Baker, Phillipsburg, NJ, USA, 99.8\%), hexane (DUKSAN PURE CHEMICALS, Ansan, Korea, 97\%), methylammonium iodide (UniRegion Bio-Tech, Hsinchu, Taiwan, $\mathrm{CH}_{3} \mathrm{NH}_{3} \mathrm{I}, 99 \%$ ), dimethyl sulfoxide (DMSO, J.T. Baker, $99.5 \%$, $\left(\mathrm{CH}_{3}\right)_{2} \mathrm{SO}, 99 \%$ ), gamma-butyrolactone (GBL, CHONEYE PURE CHEMICALS, Taipei, Taiwan, $\mathrm{C}_{4} \mathrm{H}_{6} \mathrm{O}_{2}, 99.9 \%$ ) and dimethylformamide (DMF, J.T. Baker, Phillipsburg, NJ, USA, $\left.\mathrm{C}_{3} \mathrm{H}_{7} \mathrm{NO}, 99.5 \%\right)$.

\section{2. $\mathrm{CsPbI}_{3} \mathrm{QDs}$ Fabrication}

OAm $(90 \%, 2.4 \mathrm{~mL})$, CsI (99.9\%, $0.4 \mathrm{mmol}), \mathrm{PbI}_{2}(99.9985 \%, 0.4 \mathrm{mmol})$ and DMF $(99 \%$, $10 \mathrm{~mL}$ ) were mixed and stirred continuously for $10 \mathrm{~s}$ to prepare a quantum dots precursor solution, as shown in Figure 1a. The quantum dots precursor solution $(1 \mathrm{~mL})$ was added into stirring toluene $(99.8 \%, 20 \mathrm{~mL}$ ) for $10 \mathrm{~s}$ to obtain a crude quantum dots solution, as shown in Figure 1b. The resulting crude solution was centrifuged at 11,000 rpm for $15 \mathrm{~min}$ at $10{ }^{\circ} \mathrm{C}$. The precipitate was collected and then successively dispersed in hexane. The above process was repeated several times.

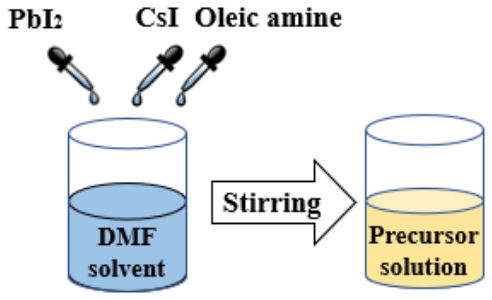

(a)

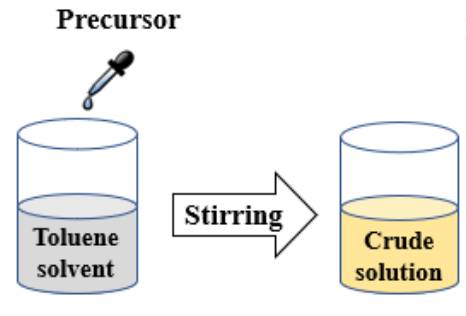

(b)

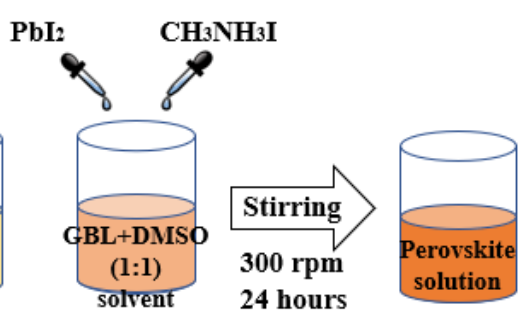

(c)

Figure 1. Schematic diagram of the PQD preparation for (a) the precursor solution to obtain (b) the crude quantum dots (QDs) solution via the ligand-assisted reprecipitation method (LARP) and (c) the $\mathrm{MAPbI}_{3}$ solution to be obtained.

\subsection{Synthesis of $\mathrm{CH}_{3} \mathrm{NH}_{3} \mathrm{PbI}_{3}$}

$\mathrm{CH}_{3} \mathrm{NH}_{3} \mathrm{I}(198.75 \mathrm{mg})$ and $\mathrm{PbI}_{2}(576.25 \mathrm{mg}$ ) were mixed into the sample bottle; then DMSO $(0.5 \mathrm{~mL})$ and GBL $(0.5 \mathrm{~mL})$ were mixed into the mixture powder. The solution was stirred at $300 \mathrm{rpm}$ for $24 \mathrm{~h}$, as shown in Figure 1c.

\subsection{Fabrication of Thin Films}

$\mathrm{CH}_{3} \mathrm{NH}_{3} \mathrm{I}(50 \mu \mathrm{L})$ and $\mathrm{CsPbI}_{3}(1 \mathrm{mg})$ were mixed and then spin-coated on a glass substrate in two steps, at $1000 \mathrm{rpm}$ for $10 \mathrm{~s}$ and $5000 \mathrm{rpm}$ for $20 \mathrm{~s}$, respectively. The main 
purpose of $1000 \mathrm{rpm}$ for $10 \mathrm{~s}$ was to make the film thickness uniform. By using high-speed rotation at $5000 \mathrm{rpm}$ for $20 \mathrm{~s}$, the purpose was to make the film thickness more uniform. Toluene was dropped on the spinning film at $15 \mathrm{~s}$ during the second step. Hereafter, the sample was heated at $80{ }^{\circ} \mathrm{C}$ for $15 \mathrm{~min}$ to form a film.

\subsection{Rapid Thermal Annealing (RTA) Process}

Finally, the annealing method of the samples was performed by rapid thermal annealing (RTA) with different temperatures $\left(100-160^{\circ} \mathrm{C}\right)$ in ambient air for $10 \mathrm{~min}$.

\subsection{Characteristic Measurements}

The absorption spectrum of the thin films was measured by ultraviolet/visible (UV/vis) absorption spectroscopy (HITACHI, U-3900, Tokyo, Japan). X-ray diffraction (XRD) data of films were recorded by the Bruker D8 Discover X-ray diffractometer (Bruker AXS Gmbh, Karlsruhe, Germany) with grazing incidence X-ray diffraction (XRD). The top-view surface morphologies of the films were determined by field-emission scanning electron microscopy (FESEM, JEOL6330 Cryo, Peabody, MA, USA). The peak intensity photoluminescence (PL) of the thin film was measured by iHR320 (HORIBA, Kyoto, Japan).

\section{Results}

Figure 2a shows the transmission electron microscope (TEM) image of $\mathrm{CsPbI}_{3} \mathrm{QDs}$. The size of $\mathrm{CsPbI}_{3}$ QDs is $16 \mathrm{~nm}$, as shown in Figure 2a, and the d-space of $\mathrm{CsPbI}_{3} \mathrm{QDs}$ is $0.30 \mathrm{~nm}$, as shown in Figure $2 \mathrm{~b}$.

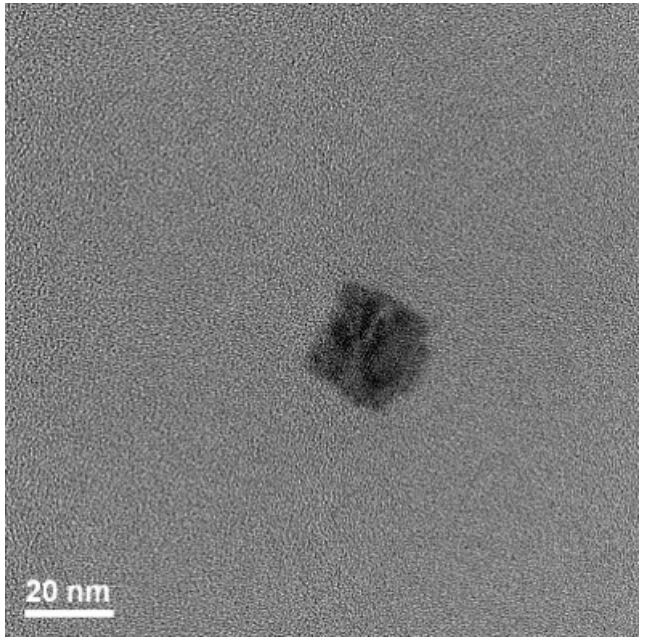

(a)

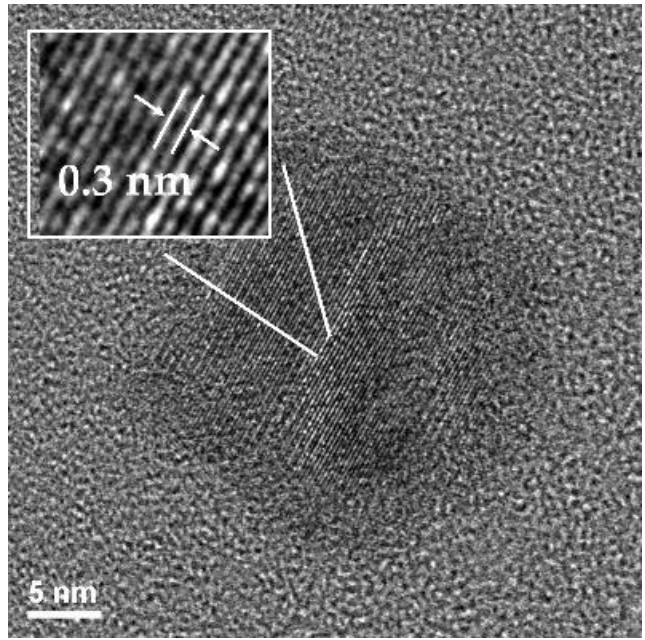

(b)

Figure 2. (a) TEM image of $\mathrm{CsPbI}_{3} \mathrm{QD}$ nanocrystals with the diameter of approximately $16 \mathrm{~nm}$. (b) HR-TEM of image (a) and enlarged image (insert).

To analyze the PQD film morphology after annealing at different temperatures, scanning electron microscope (SEM) was used to measure each sample to obtain top-view images, and the results are shown in Figure 3a-e. Figure 3 a shows the PQD film without annealing. Then, grain clusters were obviously discovered. It can be observed that the morphology of PQD film annealed at $100{ }^{\circ} \mathrm{C}$ was similar to the pristine PQD film, as shown in Figure 3b. Under this temperature, even though there was crystallization on the surface, the compactness of the film is poor. As the annealing temperature continuously increased to $120^{\circ} \mathrm{C}$, it can be observed that the compactness of the film increases and the grains are evenly distributed, as shown in Figure 3c. This was because the annealing treatment caused accumulation of the atoms in the crystal lattice, and the atoms can be rearranged and recrystallized owing to the disappearance of the vacancy. In Figure $3 d$, the grain size of the PQD film began to decrease and the vacancy between grains was more obvious when 
the annealing temperature increased to $140^{\circ} \mathrm{C}$. As the annealing temperature continuously increased to $160^{\circ} \mathrm{C}$, the change of the surface on PQD film was even more severe. In other words, PQD film was degraded if the annealing temperature was above $120^{\circ} \mathrm{C}$. Besides, the morphology of the acicular crystal was observed and the vacancy between the grains was larger because of the decrement of the grain size, as shown in Figure 3e.

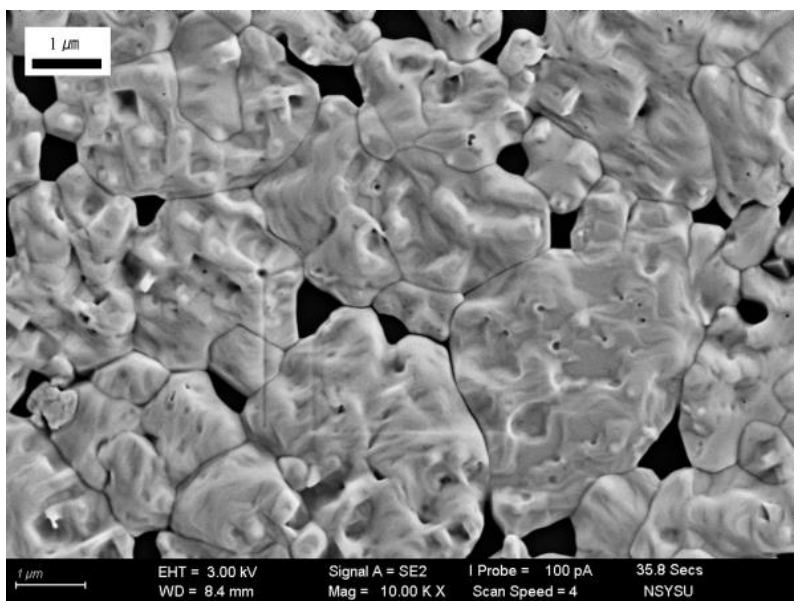

(a)

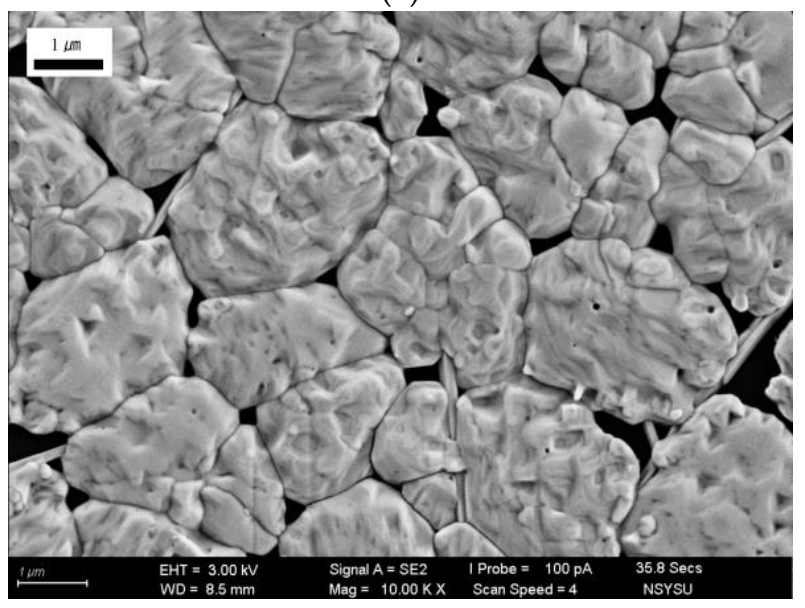

(c)

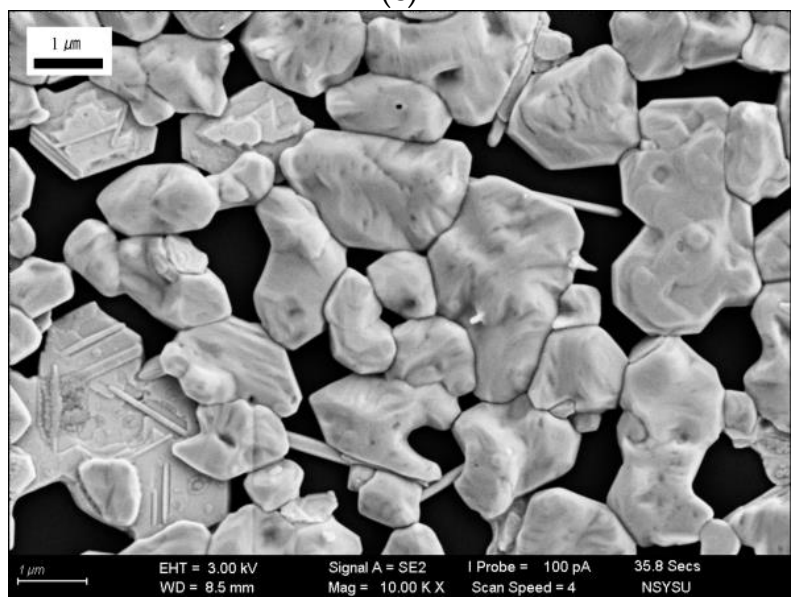

(e)

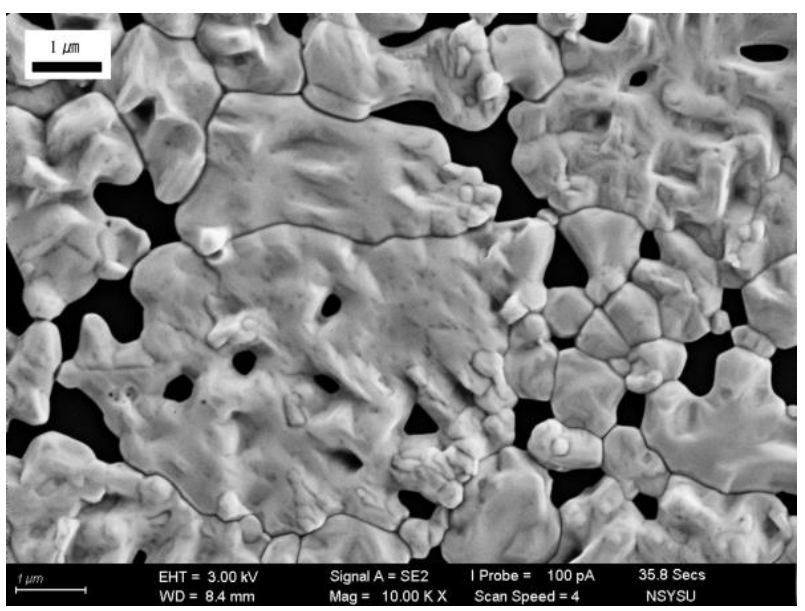

(b)

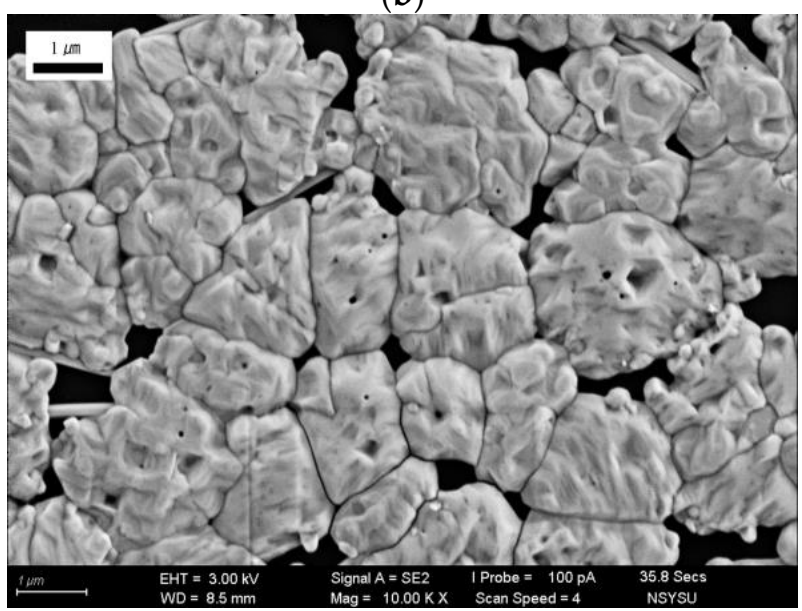

(d)

Figure 3. SEM images (top view) of (a) pristine PQD film and annealed PQD thin films at different temperatures with scale size of $1 \mu \mathrm{m}$ : (b) $100{ }^{\circ} \mathrm{C}$, (c) $120^{\circ} \mathrm{C}$, (d) $140{ }^{\circ} \mathrm{C}$, (e) $160{ }^{\circ} \mathrm{C}$. 
In Figure 4, the grain content of the PQD film formed by $\mathrm{MAPbI}_{3}$ and $\mathrm{CsPbI}_{3}$ under different annealing temperatures $\left(100-160^{\circ} \mathrm{C}\right)$ was analyzed by XRD. It can be observed that the content of the main peak was similar between pure $\mathrm{MAPbI}_{3}$ and $\mathrm{PQD}$ films without annealing, as shown in Figure $4 \mathrm{a}, \mathrm{b}$. The main peaks were, respectively, at $2 \theta=14^{\circ}$ and $2 \theta=28^{\circ}$ where the intensity of peak was weak. As the annealing temperature of PQD film increases to $100{ }^{\circ} \mathrm{C}$, it can be observed that the intensity of both PQD (110) and $\mathrm{MAPbI}_{3}(220)$ was increased. At the annealing temperature of $120^{\circ} \mathrm{C}$ for PQD film, the intensity of both PQD (110) and $\mathrm{MAPbI}_{3}$ (220) was increased even more. At the peak location of $12.7^{\circ}$, it was discovered that a small peak belonging to $\mathrm{PbI}_{2}$ (001) was also increased gradually. When the annealing temperature of PQD film continuously increased to $140{ }^{\circ} \mathrm{C}$, the intensity of PQD (110) and $\mathrm{MAPbI}_{3}$ (220) was decreased because the PQD film began to degrade. With the annealing temperature of PQD film continuously increasing to $160{ }^{\circ} \mathrm{C}$, both PQD (110) and $\mathrm{MAPbI}_{3}$ (220) nearly disappear. Besides, the intensity of $\mathrm{PbI}_{2}(001)$ was increased at annealing temperature above $120^{\circ} \mathrm{C}$. This is because PQD film was reduced into $\mathrm{PbI}_{2}$ due to over temperature. According to the literature, a small amount of $\mathrm{PbI}_{2}$ played a pivotal role in terms of the efficiency of the perovskite solar cells [17].

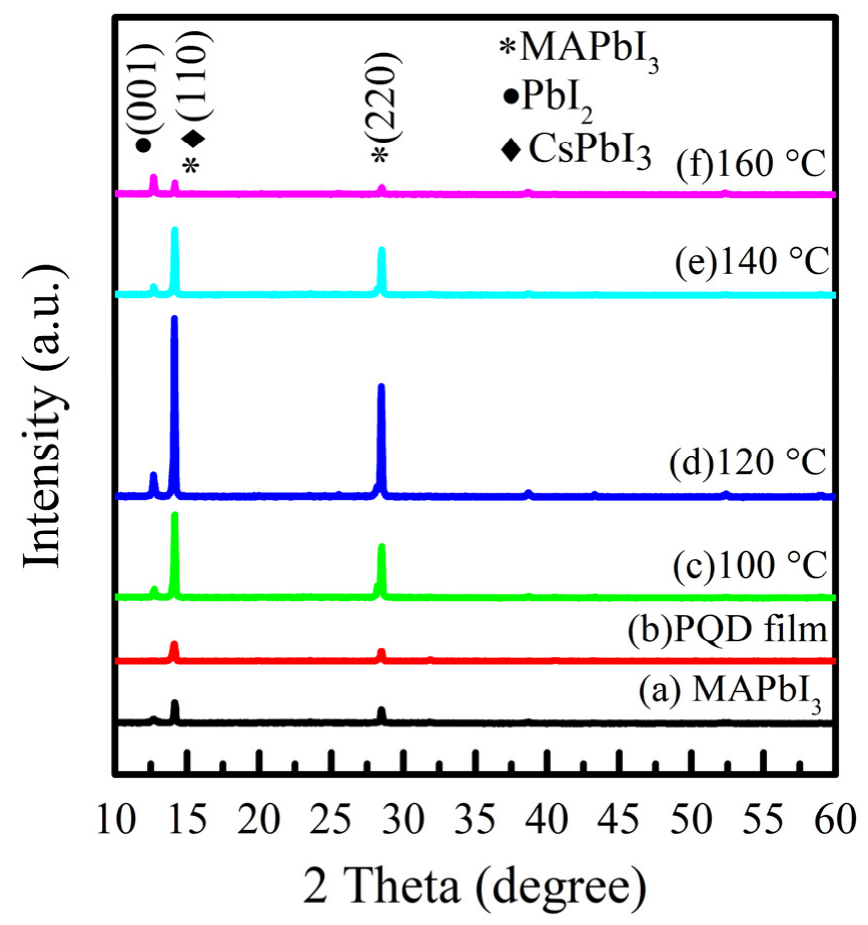

Figure 4. XRD patterns of PQD films treated at different annealing temperatures: (a) $\mathrm{MAPbI}_{3},(\mathbf{b}) \mathrm{PQD}$ film without annealing treatment, (c-f) PQD films annealing temperatures at $100-160{ }^{\circ} \mathrm{C}$.

According to the literature, PQD (110) was primarily composed of $\mathrm{CsPbI}_{3}(100)$ and $\mathrm{MAPbI}_{3}(110)[18,19]$. Therefore, peak fitting imitating software (Origin85) was used to estimate the change in area of $\mathrm{CsPbI}_{3}(100)\left(2 \theta=14.1^{\circ}\right)$ and $\mathrm{MAPbI}_{3}(110)\left(2 \theta=14.15^{\circ}\right)$ under different annealing temperatures. Figure $5 \mathrm{a}-\mathrm{c}$ indicated that as the annealing temperature increased, the area of $\mathrm{MAPbI}_{3}$ (110) gradually increased and that of $\mathrm{CsPbI}_{3}(100)$ gradually decreased. The minimum full width at half maximum (FWHM) values of $\mathrm{CsPbI}_{3}(100)$ and $\mathrm{MAPbI}_{3}(110)$ were, respectively, $0.11^{\circ}$ and $0.08^{\circ}$ at annealing temperature $120{ }^{\circ} \mathrm{C}$. This meant that there was a favorable condition to form PQD (110) at $120^{\circ} \mathrm{C}$. As the annealing temperature was up to $160{ }^{\circ} \mathrm{C}$, it was discovered that the area of $\mathrm{MAPbI}_{3}(110)$ was decreasing $(\mathrm{FWHM}=0.09)$ and that the area of $\mathrm{CsPbI}_{3}(100)$ was gradually increasing $(\mathrm{FWHM}=0.14)$. The FWHM value of both materials was gradually increasing, as shown in Figure 5d,e. 


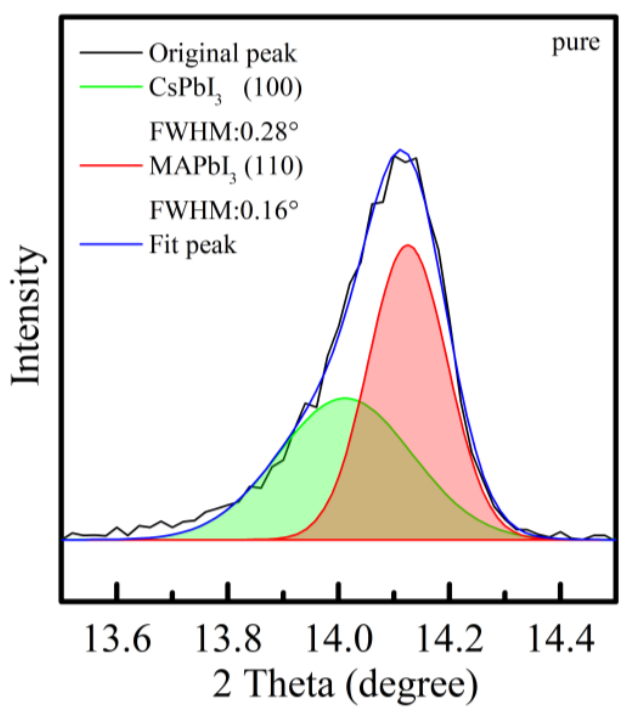

(a)

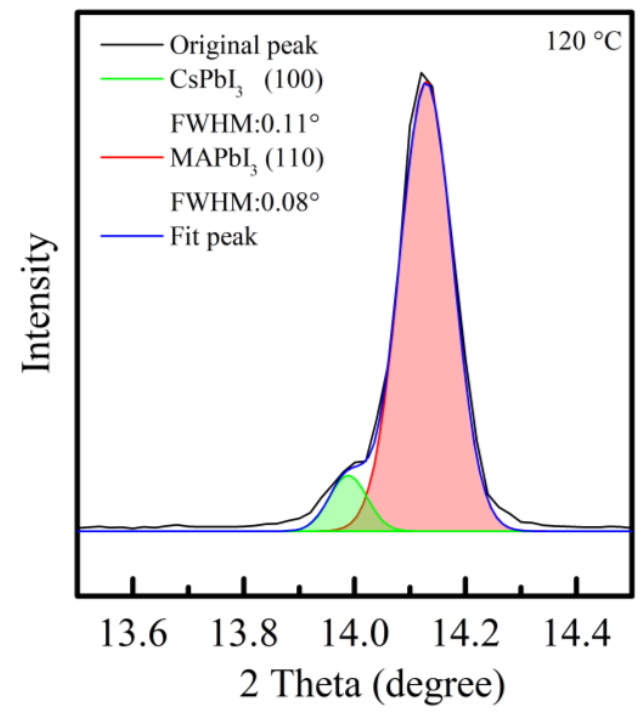

(c)

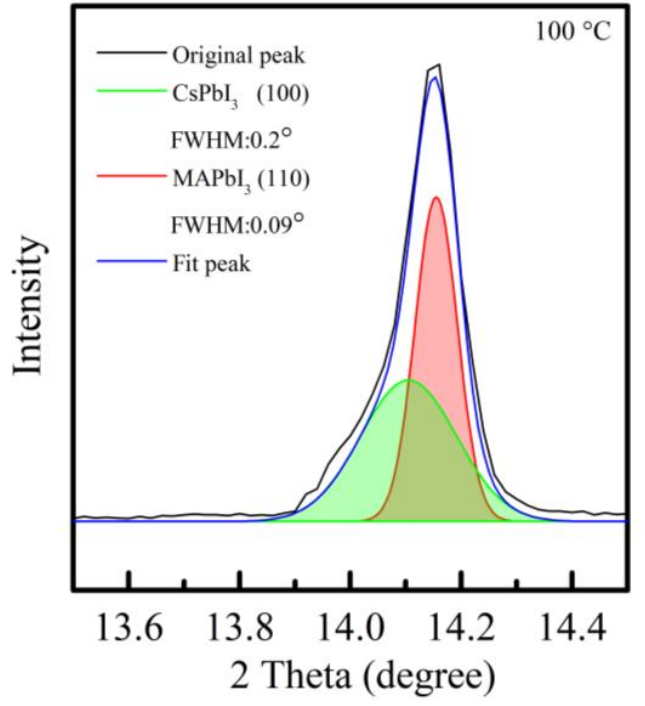

(b)

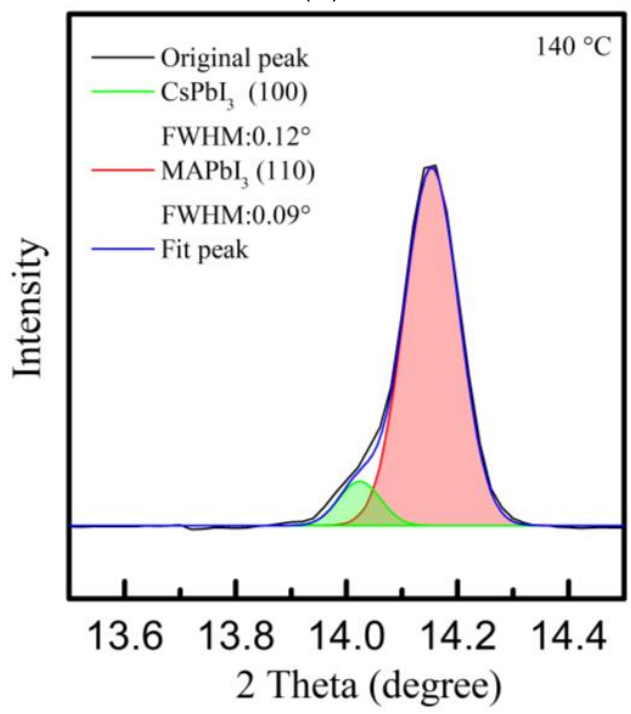

(d)

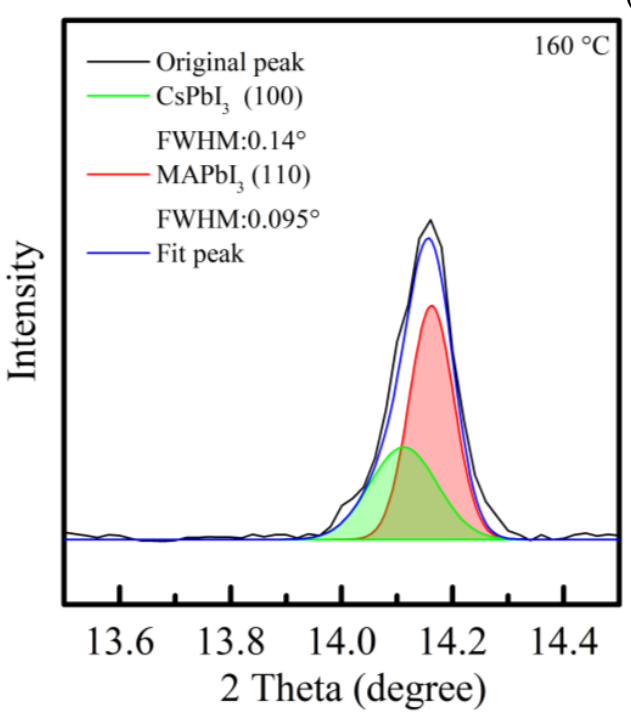

(e)

Figure 5. (a-e) XRD fitting patterns of PQD films treated at different annealing temperatures. 
Because the sunlight was resulting in generating more carriers, the grain size is larger and the efficiency of perovskite absorbing was higher [20]. Therefore, the grain size at different annealing temperatures was calculated from XRD results and Scherrer Equation (1) [21].

$$
D=\frac{k \lambda}{\beta \cos \theta}(\text { Scherrer equation })
$$

where $k$ refers to the shape factor, the value of which was approximately 0.9 . $D$ refers to the grain size (nm). $\lambda$ refers to the wavelength of the X-ray. $\beta$ refers to the FWHM value of the diffraction peak. $\theta$ refers to the diffraction angle. Calculation results indicated that the grain size of PQD film was sequentially (1) $33.7 \mathrm{~nm}$, (2) $54.6 \mathrm{~nm}$, (3) $60.2 \mathrm{~nm}$, (4) $55.6 \mathrm{~nm}$ and (5) $54.9 \mathrm{~nm}$ for (1) the untreated film, (2) under the annealing temperature of $100{ }^{\circ} \mathrm{C}$, (3) under that of $120{ }^{\circ} \mathrm{C}$, (4) under that of $140{ }^{\circ} \mathrm{C}$ and (5) under that of $160{ }^{\circ} \mathrm{C}$. Then, when the annealing temperature was at $120^{\circ} \mathrm{C}$, the maximum average grain size was $60.2 \mathrm{~nm}$, the phenomenon of which was consistent with the result, as shown in Figure 5c.

Figure 6 shows the area ratio of $\mathrm{CsPbI}_{3}$ (100) and $\mathrm{MAPbI}_{3}$ (110) under different annealing temperatures. It was revealed that the area ratio of $\mathrm{CsPbI}_{3}(100)$ and $\mathrm{MAPbI}_{3}$ (110) was approximately $1: 9$ at the annealing temperature from $120^{\circ} \mathrm{C}$ to $140{ }^{\circ} \mathrm{C}$. Besides, the area ratio of $\mathrm{CsPbI}_{3}(100)$ was decreased with the annealing temperature until $140{ }^{\circ} \mathrm{C}$. Then, most of $\mathrm{MAPbI}_{3}(110)$ were degraded into $\mathrm{PbI}_{2}$ at the annealing temperature of $160{ }^{\circ} \mathrm{C}$. Furthermore, the degradation of $\mathrm{MAPbI}_{3}$ was more susceptible to temperature than that of $\mathrm{CsPbI}_{3}$, so the ratio of $\mathrm{CsPbI}_{3}$ will be higher than that of $\mathrm{MAPbI}_{3}$ at annealing temperature of $160^{\circ} \mathrm{C}$. The maximum absorbance and the condenser film can be obtained by comparison with optical properties and SEM analysis of PQD film at annealing temperature of $120{ }^{\circ} \mathrm{C}$. Thus, this ratio is favorable for the PQD film.

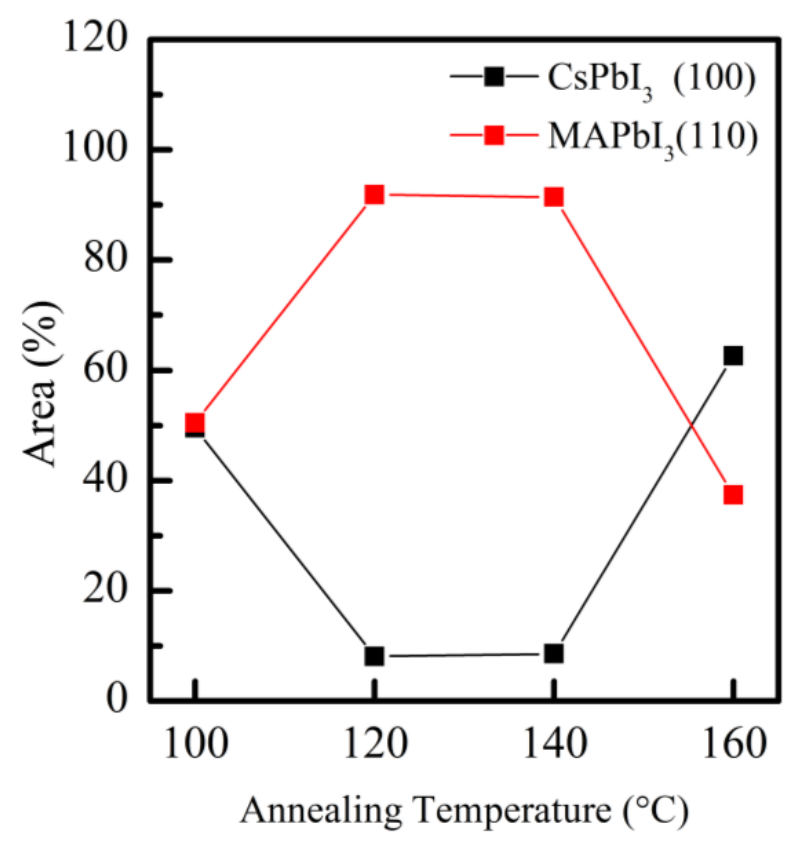

Figure 6. Area of PQD films at different annealing temperatures.

According to our previous research, the doping of a small amount of $\mathrm{CsPbI}_{3}$ QDs can obtain better thermal stability to reduce the density of surface trap states [22], with the result that perovskite grain size continuously increases and arranges closer. The phenomenon was consistent with the result, as shown in Figure 3c.

Figure 7a shows the absorption spectrum of the PQD film without annealing and at the annealing temperature of $100-160^{\circ} \mathrm{C}$. By annealing the PQD film, it was revealed that the absorbance from the whole spectrum range was enhanced, and the maximum absorption 
area occurred at $120^{\circ} \mathrm{C}$. When the annealing temperature was further increased to $160{ }^{\circ} \mathrm{C}$, absorbance begins to decrease.

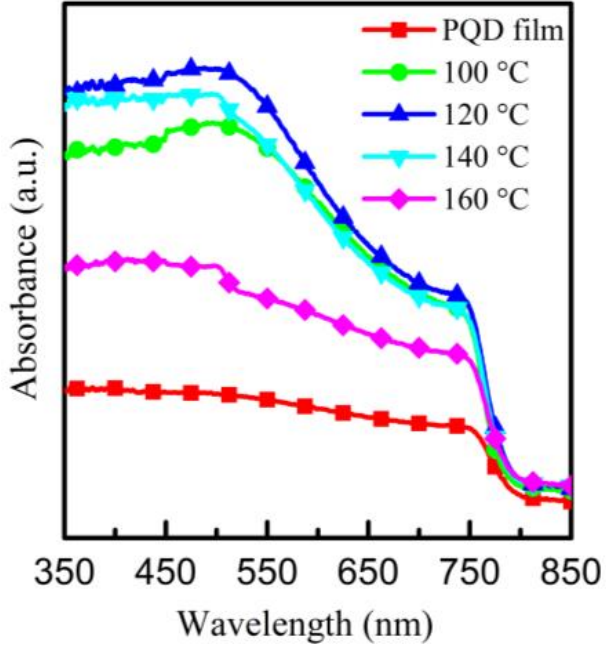

(a)

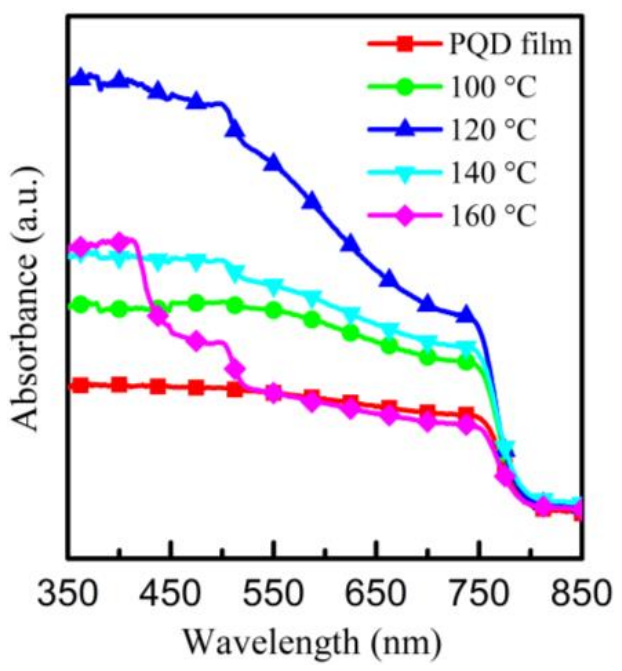

(b)

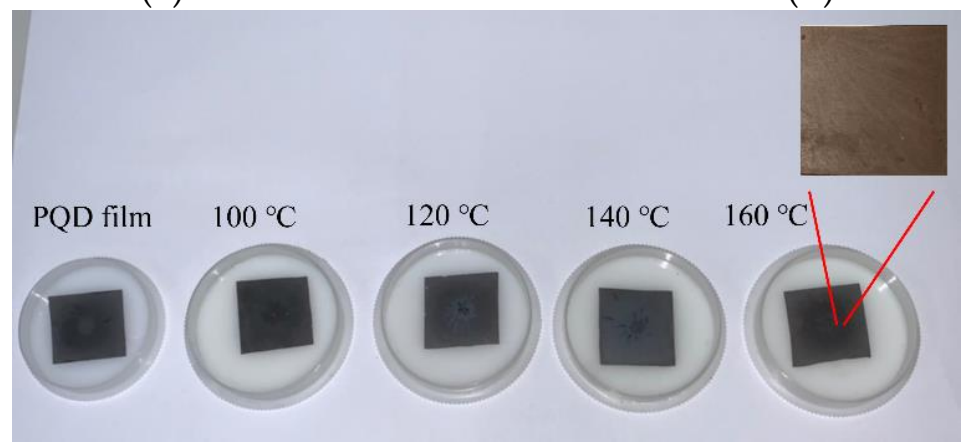

(c)

Figure 7. (a) UV-vis absorption spectra for pristine PQD films at different annealing temperatures. (b) All the above samples were stored in ambient air for $168 \mathrm{~h}$. (c) Morphology of thin film for all samples at annealed temperature of $100-160^{\circ} \mathrm{C}$ and zoom-in image (insert) at annealing temperature of $160{ }^{\circ} \mathrm{C}$.

Then all the above samples were stored in ambient air for $168 \mathrm{~h}$ to test stability of the PQD films, as shown in Figure $7 \mathrm{~b}$. It can be found that the PQD films still exhibit typical perovskite absorption spectrum after $168 \mathrm{~h}$, indicating that doping QD into perovskite can effectively resist the change of moisture and oxygen. However, at annealing temperature of $160{ }^{\circ} \mathrm{C}$, the appearance of $\mathrm{PbI}_{2}$ peak in absorption spectrum indicated that the surface of the PQD film was destroyed, with the result that the stability of PQD film became poor and part of the PQD film was degraded to $\mathrm{PbI}_{2}$. The phenomenon is consistent with the above results.

The image of the films annealed at temperature of $100-160{ }^{\circ} \mathrm{C}$ is shown as Figure $7 \mathrm{c}$. Morphology of thin film for all samples presented the perovskite black phase (named $\alpha$ phase), but partial area of surface revealed yellow $\delta$ phase at annealing temperature of $160{ }^{\circ} \mathrm{C}$, as shown in the insert image of Figure 7c.

The PL of the film at different annealing temperatures under consideration is shown in Figure 8a. It is found that the peak intensity of PL increases with temperature, but it drops after $120^{\circ} \mathrm{C}$, and it is shown that the best crystallinity of PQD will be obtained when the annealing temperature reaches $120^{\circ} \mathrm{C}$.

Figure $8 \mathrm{~b}$ shows PL measurement for pristine PQD with annealing temperature of $120{ }^{\circ} \mathrm{C}$ (black line), which was stored in ambient air for $168 \mathrm{~h}$ (red line). The difference of 
PL intensity between black line and red line is about $15 \%$, i.e., less variation. Therefore, the stability of PQD can be enhanced by annealing treatment.

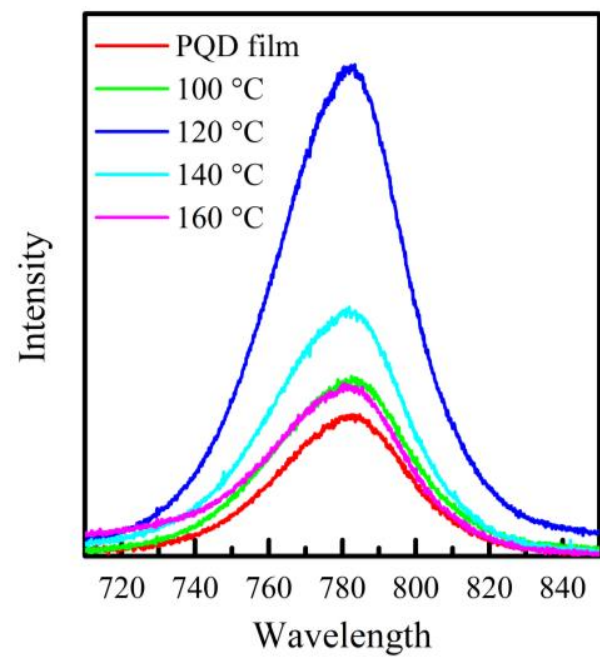

(a)

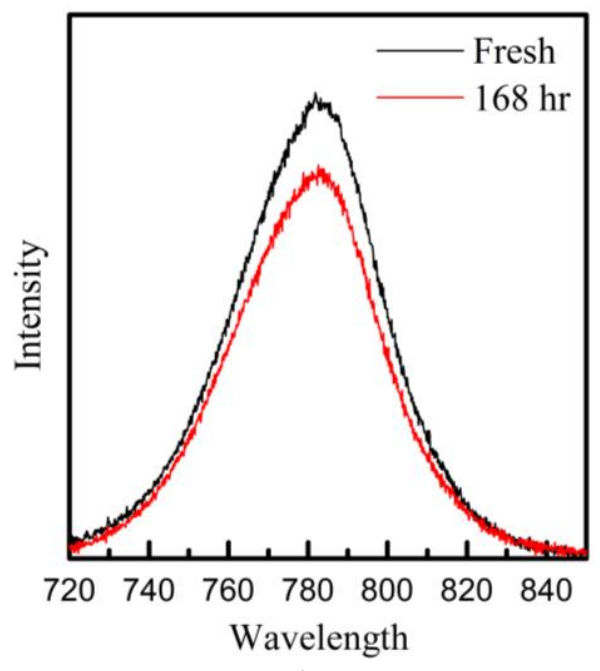

(b)

Figure 8. (a) PL measurement for pristine PQD at different annealing temperatures. (b) PL measurement for pristine PQD with annealing temperature of $120^{\circ} \mathrm{C}$ (solid square) stored in ambient air for $168 \mathrm{~h}$ (solid circle).

\section{Conclusions}

In our result, organic-inorganic doped quantum dot films were prepared to understand the reaction of perovskite films at different annealing temperatures. From the SEM images, it was found that thermal annealing treatment can cause the rearrangement of atoms in the perovskite, resulting in reduction of defects and obtaining a compactness film at $120^{\circ} \mathrm{C}$. In the XRD pattern, it was revealed that the perovskite film will obviously degrade into $\mathrm{PbI}_{2}$ when the annealing temperature reaches $160{ }^{\circ} \mathrm{C}$. This will affect the absorbance of the film. Through peak fitting imitating software to further understand the ratio of $\mathrm{MAPbI}_{3}$ to $\mathrm{CsPbI}_{3}$ at different temperatures, it was shown that a small amount of $\mathrm{CsPbI}_{3}$ can cause grain arrangement growth at $120^{\circ} \mathrm{C}$ and the grain size was $60.2 \mathrm{~nm}$.

Author Contributions: Conceptualization, S.-Y.L., P.-W.S. and P.-J.L.; formal analysis, S.-Y.L., P.-J.L. and C.-J.H.; funding acquisition, P.-J.L. and S.-Y.L.; investigation, S.-Y.L. and C.-J.H.; resources, P.-J.L.; supervision, W.-R.C., S.-Y.L., C.-H.L. and C.-J.H.; writing-original draft, P.-J.L. All authors have read and agreed to the published version of the manuscript.

Funding: This research was funded by the Ministry of Science and Technology (MOST) of the Republic of China: grant number 110-2221-E-390-019.

Data Availability Statement: The data presented in this study are available on request from the corresponding author.

Conflicts of Interest: The authors declare no conflict of interest.

\section{References}

1. Prakasam, V.; Tordera, D.; Bolink, H.J.; Gelinck, G. Degradation Mechanisms in Organic Lead Halide Perovskite Light-Emitting Diodes. Adv. Opt. Mater. 2019, 7, 1900902. [CrossRef]

2. Akkerman, Q.A.; Rainò, G.; Kovalenko, M.V.; Manna, L. Genesis, challenges and opportunities for colloidal lead halide perovskite nanocrystals. Nat. Mater. 2018, 17, 394-405. [CrossRef] [PubMed]

3. Qiao, T.; Son, D.H. Synthesis and Properties of Strongly Quantum-Confined Cesium Lead Halide Perovskite Nanocrystals. Acc. Chem. Res. 2021, 54, 1399-1408. [CrossRef] [PubMed]

4. Vidyasagar, C.C.; Flores, B.M.M.; Pérez, V.M.J. Recent advances in synthesis and properties of hybrid halide perovskites for photovoltaics. Nano-Micro Lett. 2018, 10, 1-34. [CrossRef] 
5. Yang, W.S.; Noh, J.H.; Jeon, N.J.; Kim, Y.C.; Ryu, S.; Seo, J.; Seok, S.I. High-performance photovoltaic perovskite layers fabricated through intramolecular exchange. Science 2015, 348, 1234-1237. [CrossRef]

6. Zhao, Z.; Sun, W.; Li, Y.; Ye, S.; Rao, H.; Gu, F.; Liu, Z.; Bian, Z.; Huang, C. Simplification of device structures for low-cost, high-efficiency perovskite solar cells. J. Mater. Chem. A 2017, 5, 4756-4773. [CrossRef]

7. Han, T.H.; Tan, S.; Xue, J.; Meng, L.; Lee, J.W.; Yang, Y. Interface and defect engineering for metal halide perovskite optoelectronic devices. Adv. Mater. 2019, 31, 1803515. [CrossRef]

8. Salado, M.; Contreras-Bernal, L.; Caliò, L.; Todinova, A.; López-Santos, C.; Ahmad, S.; Borras, A.; Idígoras, J.; Anta, J.A. Impact of moisture on efficiency-determining electronic processes in perovskite solar cells. J. Mater. Chem. A 2017, 5, 10917-10927. [CrossRef]

9. Mocatta, D.; Cohen, G.; Schattner, J.; Millo, O.; Rabani, E.; Banin, U. Heavily doped semiconductor nanocrystal quantum dots. Science 2011, 332, 77-81. [CrossRef]

10. Xu, L.; Yuan, S.; Zeng, H.; Song, J.J.M.T.N. A comprehensive review of doping in perovskite nanocrystals/quantum dots: Evolution of structure, electronics, optics, and light-emitting diodes. Mater. Today Nano 2019, 6, 100036. [CrossRef]

11. Niu, G.; Li, W.; Li, J.; Liang, X.; Wang, L. Enhancement of thermal stability for perovskite solar cells through cesium doping. RSC Adv. 2017, 7, 17473-17479. [CrossRef]

12. Han, J.; Luo, S.; Yin, X.; Zhou, Y.; Nan, H.; Li, J.; Li, X.; Oron, D.; Shen, H.; Lin, H. Hybrid PbS Quantum-Dot-in-Perovskite for High-Efficiency Perovskite Solar Cell. Small 2018, 14, 1801016. [CrossRef] [PubMed]

13. Zhou, Y.; Game, O.S.; Pang, S.; Padture, N.P. Microstructures of organometal trihalide perovskites for solar cells: Their evolution from solutions and characterization. J. Phys. Chem. Lett. 2015, 6, 4827-4839. [CrossRef] [PubMed]

14. Natik, A.; Moubah, R.; Abid, Y.; Zaari, H.; El Moussaoui, H.; Tamraoui, Y.; Abid, M.; Lassri, H. Annealing time effects on the structural, morphological and optical properties in hybrid $\mathrm{CH}_{3} \mathrm{NH}_{3} \mathrm{PbI}_{3}$ perovskites: Experimental and ab-initio investigations. Opt. Mater. 2020, 109, 110255. [CrossRef]

15. Bai, Z.; Zhong, H. Halide perovskite quantum dots: Potential candidates for display technology. Sci. Bull. 2015, 60, 1622-1624. [CrossRef]

16. Padchasri, J.; Yimnirun, R. Effects of annealing temperature on stability of methylammonium lead iodide perovskite powders. $J$. Alloys Compd. 2017, 720, 63-69. [CrossRef]

17. Cao, D.H.; Stoumpos, C.C.; Malliakas, C.D.; Katz, M.J.; Farha, O.K.; Hupp, J.T.; Kanatzidis, M.G. Remnant PbI ${ }_{2}$, an unforeseen necessity in high-efficiency hybrid perovskite-based solar cells? APL Mater. 2014, 2, 091101. [CrossRef]

18. Zhang, T.; Dar, M.I.; Li, G.; Xu, F.; Guo, N.; Grätzel, M.; Zhao, Y. Bication lead iodide 2D perovskite component to stabilize inorganic $\alpha-\mathrm{CsPbI}_{3}$ perovskite phase for high-efficiency solar cells. Sci. Adv. 2017, 3, e1700841. [CrossRef]

19. Pratiwi, Z.R.; Nuraeni, L.; Aimon, A.H.; Iskandar, F. Morphology control of $\mathrm{MAPbI}_{3}$ perovskite thin film as an active layer of solar cells. In IOP Conference Series: Materials Science and Engineering; IOP Publishing: Bristol, UK, 2018; Volume 395, p. 012010.

20. Jiang, Y.; Pan, L.; Wei, D.; Li, W.; Li, S.; Yang, S.E.; Shi, Z.; Guo, H.; Xia, T.; Zang, J.; et al. The modified multi-step thermal annealing process for highly efficient $\mathrm{MAPbI}_{3}$-based perovskite solar cells. Sol. Energy 2018, 174, 218-224. [CrossRef]

21. Holzwarth, U.; Gibson, N. The Scherrer equation versus the 'Debye-Scherrer equation'. Nat. Nanotechnol. 2011, 6, 534. [CrossRef]

22. Lien, S.Y.; Chen, Y.H.; Chen, W.R.; Liu, C.H.; Huang, C.J. Effect of growth temperature on the characteristics of $\mathrm{CsPbI}_{3}-\mathrm{quantum}$ dots doped perovskite film. Molecules 2021, 26, 4439. [CrossRef] [PubMed] 